\title{
INVENTÁRIO DE PRÁTICAS DOCENTES QUE FAVORECEM A CRIATIVIDADE: ESTUDO DE ADAPTAÇÃO E EVIDÊNCIAS DE VALIDADE
}

\author{
DORIS BARRINUEVO MARTINS DE LIMA ${ }^{1}$ \\ ORCID: https://orcid.org/0000-0002-1695-535X \\ GILDENE DO OURO LOPES SILVA ${ }^{2}$ \\ ORCID: https://orcid.org/0000-0002-0792-4340
}

\begin{abstract}
RESUMO: O objetivo deste estudo foi o de fazer uma adaptação do Inventário de Práticas Docentes que Favorecem a Criatividade no Ensino Superior e analisar as evidências de sua validade para o Ensino Médio. As etapas para a adaptação desse Inventário foram: adaptação semântica, avaliação de juízes e estudo piloto com 106 estudantes matriculados no Ensino Médio. O Inventário com as adequações realizadas foi aplicado em 1.118 alunos, de 30 unidades escolares de uma rede particular de ensino, distribuídas em nove estados. A análise fatorial resultou em um inventário composto por 35 itens e confirmou quatro fatores: Incentivo a novas ideias; Clima para expressão de ideias; Procedimentos tradicionais de ensino; e Interesse pela aprendizagem do aluno, os quais explicaram $44,92 \%$ da variância obtida neste estudo. A confiabilidade da análise dos dados foi adequada pelo coeficiente Lambda 2 de Guttman, que variou entre 0,61 a 0,91. Os componentes dos coeficientes de ajuste mostraram-se adequados, apresentando os seguintes valores: $A G F I=0,980$; NNFI=0,984; RMSEA=0,034; SRMR=0,049. Concluiu-se que o "Inventário de Práticas Docentes que favorecem a criatividade no Ensino Médio" constitui uma ferramenta que abre novas perspectivas para fins de futuras pesquisas e auxilia nas atitudes em âmbito educacional, quanto ao estímulo à criatividade. Sendo o fim último o que requer a contemporaneidade: professores aptos para lidar, de forma criativa, com a formação de alunos criativos.
\end{abstract}

Palavras-chave: criatividade, práticas docentes, Ensino Médio.

\section{INVENTORY OF TEACHING PRACTICES THAT FAVOR CREATIVITY: STUDY OF ADAPTATION AND VALIDITY EVIDENCE}

ABSTRACT: The objective of this study was to adapt the Inventory of Teaching Practices that Favor Creativity in Higher Education and to analyze the evidence for its validity for High School. The steps for adapting this Inventory were: a semantic adaptation, an evaluation by judges and a pilot study with 106 students enrolled at the high school level. The adjusted Inventory was applied to 1,118 students, from 30 school units in a private school network, distributed in nine states. A factor analysis resulted in an inventory consisting of 35 items and four confirmed factors: Encouragement

\footnotetext{
${ }^{1}$ Casa Publicadora Brasileira. Tatuí, SP, Brasil. <lima.doris@gmail.com>

${ }^{2}$ Centro Universitário Adventista de São Paulo. Engenheiro Coelho, SP, Brasil. < gildene.lopes@ucb.org.br >
} 
of new ideas; Favorable environment for the expression of ideas; Traditional teaching procedures; and Interest in student learning, which explained $44.92 \%$ of the variance obtained in this study. The reliability of the data analysis was calibrated by Guttman's Lambda 2 coefficient, which ranged from 0.61 to 0.91 . The components of the adjustment coefficients proved to be adequate, presenting the following values: AGFI $=0.980 ; \mathrm{NNFI}=0.984$; $\mathrm{RMSEA}=0.034 ;$ SRMR $=0.049$. It was concluded that the "Inventory of Teaching Practices that favor creativity in High School" is a tool that opens new perspectives for the purpose of future research and helps adequate educational attitudes to stimulate creativity. The end result is compatible to a contemporaneous requirement: that teachers become able to deal creatively with creative students.

Keywords: creativity, teaching practices, High school.

\section{INVENTARIO DE PRÁCTICAS DIDÁCTICAS QUE FAVORECEN LA CREATIVIDAD: ESTUDIO DE ADAPTACIÓN Y EVIDENCIA DE VALIDEZ}

RESÚMEN: El objetivo de este estudio fue adecuar el Inventario de Prácticas Docentes que Favorecen la Creatividad en la Educación Superior y analizar la evidencia de su validez para la enseñanza media. Los pasos para adaptar este Inventario fueron: una adaptación semántica, una evaluación por jueces y un estudio piloto con 106 estudiantes matriculados en el nivel secundario. El Inventario ajustado se aplicó a 1,118 estudiantes, de 30 unidades escolares en una red de escuelas privadas, distribuidas en nueve estados. El análisis factorial resultó en un inventario que constaba de 35 artículos y cuatro factores confirmados: Fomento de nuevas ideas; Entorno favorable para la expresión de ideas; Procedimientos de enseñanza tradicionales; e Interés por el aprendizaje de los estudiantes, lo que explica el 44,92\% de la varianza obtenida en este estudio. La confiabilidad del análisis de datos se calibró mediante el coeficiente Lambda 2 de Guttman, que osciló entre 0,61 y 0,91. Los componentes de los coeficientes de ajuste resultaron adecuados, presentando los siguientes valores: AGFI $=0.980 ; \mathrm{NNFI}=0,984 ; \mathrm{RMSEA}=0,034 ; \mathrm{SRMR}=0,049$. Se concluyó que el "Inventario de Prácticas Docentes que favorecen la creatividad en la Enseñanza Media" es una herramienta que abre nuevas perspectivas con fines de investigación futura y ayuda a las actitudes educativas adecuadas para estimular la creatividad. El resultado final es compatible con un requisito contemporáneo: que los profesores sean capaces de tratar creativamente con estudiantes creativos.

Palabras clave: creatividad, prácticas de enseñanza, Escuela Secundaria. 


\section{INTRODUÇÃO}

O século XIX foi marcado pela industrialização, e o século XX, pelos avanços científicos e do conhecimento. Já o século XXI chama a atenção para a criatividade, por verificar que novas ideias e soluções de muitos problemas têm surgido em uma sociedade de mudanças (DE LA TORRE; VIOLANT, 2006). Sob essa perspectiva, as pesquisas desenvolvidas sobre a criatividade no campo educacional têm buscado compreender o seu papel no cotidiano da sala de aula (ALENCAR; FLEITH, 2010; ALENCAR; BRUNO-FARIA; FLEITH, 2010; FLEITH; ALENCAR, 2005, 2006, 2008; FLEITH; ALMEIDA; PEIXOTO, 2011; LUBART, 2009; MARTÍNEZ, 1997, 2002, 2008, 2009; SILVA; FADEL; WECHSLER, 2013; WECHSLER, 2002b, 2004, 2017; KAUFMAN, 2018; JAUK, et al. 2019; VINCENT-LANCRIN, et al. 2020).

Embora não seja recente o reconhecimento da criatividade nas ações educativas, cada vez mais torna-se necessário repensar a educação pelo viés da criatividade (HAETINGER, 2012). A sociedade atual necessita de novas metas educativas que favoreçam o desenvolvimento da criatividade nas orientações metodológicas (DE LA TORRE, 2008). Nesse contexto, há que mencionar a importância do trabalho pedagógico criativo para o cultivo de novos conhecimentos e novas habilidades, já que toda prática docente criativa estimula a aprendizagem e o desenvolvimento dos estudantes (MARTÍNEZ, 1997).

Entretanto, o desenvolvimento da criatividade no contexto escolar tem sido um dos desafios que a escola enfrenta, principalmente quando se espera do professor o uso de estratégias de ensino mais adequadas e favorecedoras da criatividade (WECHSLER, 2002b). Isso requer, então, práticas de ensino com vistas à promoção de um ambiente favorecedor da expressão criativa do estudante (ALENCAR, 2002). Ademais, Batista, Luz e Brum (2015) apontam para a compreensão do professor em relação ao desenvolvimento das práticas criativas, uma vez que ele exerce um papel fundamental sobre a formação do estudante.

Contudo, simultaneamente ao reconhecimento de um ensino que invista no desenvolvimento das habilidades criativas de estudantes e professores, verifica-se a existência de dificuldades relacionadas a esse objetivo. Nesse sentido, Wechsler (2002a) alerta para pontos que estariam impedindo o professor de ousar e utilizar estratégias criativas em suas aulas, por exemplo, o despreparo do professor, sua formação e barreiras pessoais. No estudo de Oliveira e Alencar (2010), os professores do curso de Letras acrescentaram à lista das dificuldades relacionadas com a criatividade as seguintes condições: o ensino tradicional e conteudista que receberam em sua formação, o desconhecimento do tema "criatividade" e a ausência de atualização na sua formação. Além dessas condições de natureza pessoal, que exercem influência no processo criativo, 
Csikszentmihalyi (2007) destaca também as de ordem externa, como os recursos tecnológicos e metodológicos adequados à produção criativa. Oliveira e Alencar (2010) questionam a necessidade de uma abordagem em duas frentes, quando o elemento criatividade é presente no cotidiano da sala de aula: a primeira tem a ver com o professor, que deve estar disposto a encontrar alternativas de ensino; e a segunda refere-se ao aluno, o qual precisa estar sensível aos processos de criação. Em complemento, Alencar (2007) alerta sobre a relevância da conscientização do professor em relação às suas habilidades criativas, além do conhecimento de outros procedimentos pedagógicos que podem desenvolver a criatividade do estudante e, ainda, dos vários fatores que se associam à expressão criativa tanto do professor quanto do aluno.

O investimento em condições de ensino criativo requer uma atitude criativa do professor, o qual, de acordo com De La Torre (2012), para lidar com essa atitude, deve ampliar os seus horizontes de modo que possa lidar facilmente com a complexidade, objetivando a capacidade de entusiasmar, inovar, ajudar e promover a aprendizagem autônoma, além disso ele deve variar as suas estratégias de ensino e cultivar emocionalmente o estudante, bem como transmitir valores. Então, é positivo, já que traz resultados, o muito tempo que se tem dedicado ao desenvolvimento de professores criativos, os quais estimulam a criatividade dos estudantes (TORRANCE, 1995). É na escola que o espírito curioso é estimulado e conservado, pois é lá que se pode encantar os alunos por meio de aulas prazerosas, sendo, para isso, necessário acabar com as barreiras à expressão criativa que existem nas escolas e propiciar um ambiente formador de alunos criativos (ALENCAR; FLEITH, 2003; OLIVEIRA; ALENCAR, 2010).

É necessário também que existam, no ambiente escolar, condições de estimular a criatividade do alunato nos diferentes níveis de ensino, desde a Educação Infantil até o Ensino Superior (WECHSLER; NAKANO, 2011). Ainda, Wechsler (2017) acrescenta que, quando a criatividade é estimulada na sala de aula, ela gera novas formas de pensar e de utilizar conhecimentos, enfocando-os sob diferentes paradigmas.

Pesquisas têm sido desenvolvidas demonstrando a importância de se ter um programa para desenvolver a criatividade na educação (FADEL, 2010; NAKANO, 2011). Fadel (2010) avaliou os efeitos de um programa de desenvolvimento de criatividade entre docentes do Ensino Superior e percebeu que o programa contribui favoravelmente para a formação desses profissionais. Ademais, Nakano (2011) fez uma revisão sistemática, em quatro bases de dados, sobre os programas de treinamento e criatividade e a forma como vêm sendo implantados, verificando que há resultados positivos quando se utilizam técnicas diferenciadas e planejamento diversificado. 
Então, as práticas docentes criativas emergem como algo a ser investigado, com vistas à promoção da criatividade no cotidiano da docência, de modo que tantos os professores quanto os estudantes compreendam as práticas que atendam a esse objetivo. Nesse sentido, é relevante analisar a percepção do estudante quanto às práticas criativas de seus professores (ALMEIDA, 2010; BRAUM; CARMO; SÁ, 2016; CASSOL; CANELA; RUAS, 2014; MORAIS, ALMEIDA; AZEVEDO; ALENCAR; FLEITH, 2014; RIBEIRO, 2006; SATHLER, 2007), bem como verificar a autopercepção dos professores quanto às suas próprias práticas (ALENCAR; FLEITH, 2010; RIBEIRO, 2006).

Entende-se que tais reflexões sobre a própria prática docente contribuem para aulas mais criativas e que favoreçam a criatividade dos alunos (ALENCAR; FLEITH, 2004, 2010). Portanto, a percepção dos estudantes quanto às práticas docentes criativas dos seus professores é muito importante, bem como a escuta destes em relação às opiniões dos alunos (ALENCAR; FLEITH, 2004, 2010). Em complemento, Nuñez e Santos (2012) afirmam a necessidade de o professor ter uma escuta sensível, pois isso facilita o diálogo na prática docente e estabelece a confiança entre professor e estudante.

Assim, é compreensível o investimento em condições de ensino criativo na formação do docente (MARTÍNEZ, 2002). De modo semelhante, Wechsler (2017) constata a urgência em formar professores criativos. A literatura aponta a precariedade, de forma geral, na formação do professor (ALENCAR; FLEITH, 2010; MARTÍNEZ, 2002; WECHSLER, 2017). Alencar e Fleith (2010) afirmam que os cursos de formação oferecem uma educação que privilegia a reprodução e a memorização, e isso contribui para que o professor chegue à sala de aula despreparado para uma prática criativa.

Tendo em vista a importância da criatividade na formação da prática docente, Ribeiro e Fleith (2007), em seus estudos, concluíram pela necessidade de promover uma formação docente voltada para a criatividade, contribuindo, assim, não só para enriquecer o conhecimento dos envolvidos como também para desenvolver, na sala de aula, a expressão criativa dos alunos. Desse modo, é compreensível que se conheça acerca das práticas docentes que têm favorecido o desenvolvimento da criatividade dos estudantes.

Observa-se, na literatura, que a maioria dos instrumentos na área da criatividade que focam a identificação das práticas docentes criativas é utilizado, especialmente, no cenário do Ensino Superior (ALENCAR; FLEITH, 2004, 2010; BRICEÑO, 2014; FROSSARD, 2013; GONTIJO, 2007; LIBÓRIO, 2009; MILIAN, 2014; MORAIS; ALMEIDA; AZEVEDO; ALENCAR; FLEITH, 2014; NAKANO, 2006; SUÁREZ, 2014). A escassez de instrumentos com 
esse objetivo, no contexto do Ensino Médio, foi observada pela identificação de que apenas dois dos estudos encontrados optaram por esse nível de ensino (ALMEIDA, 2010).

Considerando a fundamental importância dos docentes em repensarem suas práticas, o que, na opinião dos estudantes, contribui para o desenvolvimento de seu potencial criativo, tendo em vista que as pesquisas com esse intuito se mostram incipientes no contexto do Ensino Médio, o objetivo deste estudo é o de adaptar e obter evidências da validade, para o Ensino Médio, do Inventário de Práticas Docentes que Favorecem a Criatividade no Ensino Superior (ALENCAR; FLEITH, 2004), na percepção de estudantes do Ensino Médio.

\section{MÉTODOS}

\section{Participantes}

A amostra final da pesquisa foi de 1.118 estudantes do Ensino Médio de uma rede educacional particular de São Paulo, no Brasil, tendo em vista a possibilidade de que, quanto maior for o número de sujeitos, menor será o efeito do erro amostral (MACCALLUM; WIDAMAN; ZHANG; HONG, 1999). Pretendendo assegurar a maior representatividade nacional, a amostra contemplou 30 Unidades Escolares, distribuídas em nove estados, assim representada: Amazonas $(\mathrm{n}=237,21,3 \%)$, Bahia $(\mathrm{n}=147,13,2 \%)$, Minas Gerais $(\mathrm{n}=15,1,34 \%)$, Mato Grosso do Sul ( $\mathrm{n}=52$, 4,65\%), Pará ( $n=71,6,36 \%)$, Pernambuco $(n=20,1,70 \%)$, Paraná $(n=108,9,61 \%)$, Rio de Janeiro ( $\mathrm{n}=47,4,20 \%)$, São Paulo ( $\mathrm{n}=421,37,64 \%)$.

A idade média dos estudantes participantes foi de 16,3 anos $(\mathrm{DP}=0,97)$, variando entre 13 e 20 anos. Do total de participantes, 633 (56,6)\% eram mulheres e 485 (43,4\%), homens. Ainda, $305(27,3 \%)$ estudantes cursavam o primeiro ano, 450 (40,3\%), o segundo ano, e 363 (32,4\%), o terceiro ano do Ensino Médio.

Embora a amostra tenha sido ampla e representativa em relação às diferentes regiões do Brasil e aos anos do Ensino Médio, a limitação da coleta de dados a estudantes de uma única rede de ensino particular não permite a possibilidade de generalização dos resultados. No entanto, essa limitação foi um dos fatores que assegurou um número mais expressivo de participantes, pelo apoio dos gestores educacionais das regiões administrativas, em cada estado, na realização da pesquisa. Além disso, houve a disponibilidade dos recursos necessários para o acesso dos participantes ao instrumento de coleta de dados.

Os critérios de inclusão dos estudantes participantes na pesquisa foram: ser matriculado regularmente no Ensino Médio, em uma das Unidades Escolares oriundas do estudo; 
e concordar com os Termos de Assentimento e Consentimento Livre e Esclarecido. A pesquisa foi aprovada pelo Comitê de Ética em Pesquisa, com o parecer consubstanciado número 2.270.171, sob o registro CAAE: 73521717.7.0000.5377, em 12 de setembro de 2017.

\section{Instrumento}

O instrumento utilizado foi o Inventário de Práticas Docentes que Favorecem a Criatividade no Ensino Superior, desenvolvido por Alencar e Fleith (2004). Esse instrumento original foi constituído por 38 itens, no formato Likert de cinco pontos, que variam entre "discordo plenamente" e "concordo plenamente". As evidências de validade desse instrumento foram estabelecidas por análise exploratória dos dados, utilizando-se o pacote estatístico SPSS 8.0, com rotação oblíqua (oblimin), e considerou-se como critério de retenção dos fatores eigenvalue igual ou maior do que 1,0. Os resultados geraram quatro fatores: (a) incentivo a novas ideias; (b) clima para expressão de ideias; (c) avaliação e metodologia de ensino; (d) interesse pela aprendizagem do estudante. Posteriormente, esse instrumento foi utilizado em pesquisas como as de Sathler (2007) e Morais et al. (2014). Em todos os estudos, não foi realizada adaptação e análise das evidências de validade para o contexto do Ensino Médio, sendo isso mais explorado no Ensino Superior.

\section{Adaptação do instrumento}

As etapas para a realização da adaptação do instrumento foram as sugeridas por Cassepp-Borges, Balbinotti e Teodoro (2010), que são: autorização das autoras do instrumento original; adaptação semântica, que exige planejamento e rigor quanto à manutenção do conteúdo do instrumento; características e validade para o nível desejado da população a que se destina, por meio da avaliação de juízes e estudo piloto.

Com a autorização das autoras do instrumento, a pesquisa deu prosseguimento à adaptação semântica, que foi realizada em três encontros, com a participação da pesquisadora e de três juízes, sendo eles: um mestre em Língua Portuguesa, experiente na área educacional e na editoração de livros e periódicos para adolescentes e jovens; e dois doutores em Psicologia, com pesquisas na área da criatividade e experiência no contexto do Ensino Médio. Essa adaptação buscou garantir o sentido dos itens originais, evitando ambiguidades e formulações pouco apropriadas, de modo que isso favorecesse a compreensão do público-alvo (GÜNTTER, 2003; PRIMI; MUNIZ; NUNES, 2009), visto que, nesse nível de ensino, ainda é requerida, tanto para o professor quanto para o aluno, uma linguagem específica (LOPES, 2018). 
Após esse procedimento, o estudo piloto foi realizado em uma das unidades escolares da rede educacional particular do Estado de São Paulo participante da pesquisa, que foi escolhida por conveniência. Conforme data e horário previamente agendados, foi realizada a aplicação do instrumento, pela pesquisadora, em 106 estudantes matriculados no Ensino Médio, em suas respectivas classes (salas de aula). Desses, 38 estudantes (35,8\%) pertenciam ao primeiro ano; 36 (34,0\%), ao segundo ano; e 32 (30,2\%), ao terceiro ano. Sendo que 59,44\% (n=63) dos participantes eram do gênero feminino e 40,56\% ( $n=43)$, do gênero masculino. As idades variaram entre 13 e 19 anos $(\mathrm{M}=15,92 ; \mathrm{DP}=1,045)$.

Inicialmente, explicou-se para os alunos o objetivo do estudo e as orientações para o preenchimento do instrumento, sendo que não houve limitação de tempo. Além disso, a pesquisadora ficou à disposição dos estudantes para esclarecer as possíveis dúvidas. Destaca-se que foram acrescentadas no instrumento duas questões de respostas abertas: a de número 39 (Você achou as questões difíceis?) e a 40 (Teve alguma questão que você não entendeu? Qual(is)?). Com isso, pretendeu-se compreender possíveis dificuldades na resposta dos itens.

Ao analisar os dados coletados, verificou-se que os itens 6, 8, 13, 17 e 31 não foram compreensíveis, entendidos como confusos por 23 (21,6\%) estudantes-participantes. Desses 23 estudantes, $100 \%$ deles não entenderam os itens 6 e 31; 69\%, não entenderam o item 8; 56\%, não entenderam o item 13; 78\%, não entenderam o item 17. No Quadro 1, a seguir, é possível visualizar a reformulação desses itens com o objetivo de melhorar a compreensão do público-alvo.

Quadro 1 - Descrição dos itens na etapa de adaptação, mediante dados do estudo piloto

\begin{tabular}{ll}
\hline \multicolumn{1}{c}{\begin{tabular}{c}
\multicolumn{1}{c}{ ITENS ORIGINAIS DO INVENTÁRIO } \\
APLICADO NO ESTUDO PILOTO
\end{tabular}} & $\begin{array}{l}\text { ITENS ADAPTADOS MEDIANTE DADOS DO } \\
\text { ESTUDO PILOTO }\end{array}$ \\
\hline 6. Promovem a autoconfiança nos estudantes. & $\begin{array}{l}\text { 6. Promovem a autoconfiança nos estudantes } \\
\text { (confiança em si mesmo). }\end{array}$ \\
$\begin{array}{ll}\text { 8. Incentivam os estudantes a serem independentes. } \\
\text { 8. Incentivam os estudantes a serem independentes nos } \\
\text { estudos. }\end{array}$ \\
$\begin{array}{l}\text { 13. Preocupam-se somente com a apresentação de } \\
\text { temas, não reservando tempo para debates e reflexões } \\
\text { sobre esses assuntos. }\end{array}$ & $\begin{array}{l}\text { conteúdos, não reservando tempo para debates e } \\
\text { reflexões. }\end{array}$ \\
$\begin{array}{l}\text { 17. Utilizam formas de avaliação que exigem dos } \\
\text { estudantes apenas a reprodução dos conteúdos } \\
\text { mencionados nos materiais didáticos. }\end{array}$ & $\begin{array}{l}\text { 17. Utilizam formas de avaliação que exigem dos } \\
\text { estudantes apenas a reprodução dos conteúdos } \\
\text { estudados. }\end{array}$ \\
$\begin{array}{l}\text { 31. Conversam com os estudantes sobre os resultados } \\
\text { obtidos em atividades e avaliações, incentivando-os a } \\
\text { alcançar um desempenho cada vez melhor. }\end{array}$ & $\begin{array}{l}\text { 31. Incentivam os estudantes a alcançar um } \\
\text { desempenho escolar cada vez melhor. }\end{array}$ \\
\hline
\end{tabular}

Fonte: Quadro elaborado pelas autoras, a partir dos dados da pesquisa.

Após a reformulação dos itens gerados pelos dados do estudo piloto, o instrumento foi novamente aplicado aos alunos que participaram da coleta desses dados, a fim de preencherem 
apenas os itens que sofreram adequação. Nessa última etapa da aplicação do inventário, a análise dos dados mostrou que 100\% dos alunos participantes não indicaram dificuldades com relação aos itens apresentados. Assim sendo, o "Inventário de Práticas Docentes para a Criatividade no Ensino Médio" tornou-se a versão utilizada para a próxima etapa do estudo, constituída por 38 itens, em uma escala Likert de cinco pontos.

\section{Procedimento de coleta de dados}

A coleta de dados teve o apoio da equipe pedagógica e do departamento de informática de cada unidade escolar participante da pesquisa, em um total de 50 profissionais, os quais colaboraram em todo esse processo. Para tanto, realizou-se duas reuniões com esse grupo, via Webex - um sistema de videoconferência que permite a interatividade com o grupo. A primeira reunião ocorreu com o intuito de explicar os objetivos da pesquisa, seus aspectos éticos e os procedimentos de coleta de dados. Posteriormente, em data e hora previamente agendadas, realizou-se um segundo treinamento mais específico sobre os procedimentos de coleta de dados, principalmente em relação ao envio do link do Google Forms ${ }^{3}$ para os participantes, o qual ficou disponível por 30 dias, para que os alunos respondessem ao questionário, enquanto eram monitorados pelos profissionais que colaboraram com a pesquisadora na realização da coleta de dados.

Heidemann, Oliveira e Veit (2010) destacam que, entre as vantagens de usar esse aplicativo, encontram-se: a economia de tempo no processo de coleta, o que proporciona melhores condições para fazer a análise dos dados; a facilidade de acesso aos arquivos em qualquer local ou horário; a gratuidade do aplicativo; e o fato de os dados não ocuparem espaço no computador, uma vez que são armazenados no servidor da Google. Além disso, o aplicativo monitora a quantidade de respostas e os resultados, sendo que, uma vez finalizada a coleta dos dados, estes podem ser exportados em uma planilha de diversos formatos (MATHIAS; SAKAI, 2012).

\section{Análise dos dados}

Os dados coletados foram organizados em planilhas, e neles, visando atender ao objetivo deste estudo, utilizou-se a Análise Fatorial Confirmatória (AFC), que parte da premissa de que já existe uma teoria sobre quais variáveis medem determinados fatores, de modo a confirmar o grau de ajustes dos dados observados à luz da teoria do instrumento original (BROWN, 2015;

\footnotetext{
${ }^{3}$ Google Forms é um aplicativo para elaboração de formulários on-line pertencente ao Google,
} 
HAIR JR.; ANDERSON; TATHAM; BLACK, 2009). Para fins de melhor compreensão, neste estudo, o Inventário de Práticas Docentes que Favorecem a Criatividade no Ensino Superior, de Alencar e Fleith (2004), será tratado como modelo teórico, e a AFC, como modelo hipotético.

A análise dos dados foi feita com base no método Quadrados Mínimos Ponderados Robustos, ou Weighted Least Squares Mean and V ariance (WLSMV), do pacote Lavaan do software R 3.4. Foram empregados índices de ajustes para testar as propriedades psicométricas do instrumento, como o teste qui-quadrado $\left(\mathrm{X}^{2}\right)$, o Goodness-of-Fit Index (AGFI), o Non-Normed Fit Index (NNFI), o Root-Mean Square Error of Approximation (RMSEA) e o Standardized Root Mean Square Residual (SRMR).

\section{RESULTADOS E DISCUSSÕES}

Inicialmente, será apresentado o teste do qui-quadrado $\left(\mathrm{X}^{2}\right)$, que serve para comparar se há diferença significativa entre os valores observados e os valores esperados. Os coeficientes de ajustes foram testados com o modelo unifatorial, isto é, com um só fator, e com os quatro fatores previstos na teoria, para verificar qual seria o melhor ajuste. Tais coeficientes podem ser visualizados na Tabela 1.

Tabela 1 - Coeficientes de ajustes

\begin{tabular}{|c|c|c|c|}
\hline MODELO & g.l. & $\mathbf{X}^{2}$ & $p$ \\
\hline Unifatorial & 560 & 1777,465 & $>0,001$ \\
\hline Teórico (4 fatores) & 545 & 1244,298 & $>0,001$ \\
\hline
\end{tabular}

Nota: Definição: $\mathrm{X}^{2}=$ qui-quadrado; g.l. = graus de liberdade; $p=$ significância.

Fonte: Tabela elaborada pelas autoras, a partir dos dados da pesquisa.

Entretanto, devido à sensibilidade do $\mathrm{X}^{2}$ ao tamanho amostral (DAMÁSIO, 2012; SCRABIS-FLETCHER; SILVERMAN, 2010) e ao $p$, que, para critério de avaliação, precisa ser $>0,05$ (KLINE, 2005), optou-se por utilizar outros índices de ajustes, como o AGFI, NNFI, RMSEA, SRMR, que são menos sensíveis ao tamanho da amostra (NORONHA; PINTO; OTTATI, 2016). Esses índices podem ser visualizados na Tabela 2.

Tabela 2 - Coeficientes de ajustes da Análise Fatorial Confirmatória - AFC

\begin{tabular}{lrrrrr}
\multicolumn{1}{c|}{ MODELO } & \multicolumn{2}{c|}{ AGFI } & NNFI & RMSEA & \multicolumn{2}{c}{ SRMR } \\
\hline Unifatorial & 0,973 & 0,972 & 0,044 & 0,057 \\
Teórico (4 fatores) & 0,980 & 0,984 & 0,034 & 0,049 \\
\hline
\end{tabular}


Fonte: Tabela elaborada pelas autoras, a partir dos dados da pesquisa.

O índice AGFI mostra quão bem ajustados os dados deste estudo estão à matriz de covariância do modelo original. Conforme Jörskog e Sörbom (2012) e Marôco (2010), esse índice compreende valores entre 0 e 1 , porém, quanto mais próximo do 1 , melhor é o ajustamento. Neste estudo, pode-se verificar que os dois modelos observados alcançaram valores $>0,90$, sendo o valor do modelo teórico $(0,980)$ um pouco maior do que o do unifatorial $(0,973)$.

O NNFI é um índice relativo, isto é, ele faz comparação entre o modelo hipotético e o teórico. Esse índice segue a mesma lógica do AGFI, isto é, quanto mais próximo de 1, melhor é o ajustamento. Inicialmente, valores maiores que 0,90 são desejados (BENTLER; BONETTT, 1980). Assim, verifica-se que os dois modelos apresentaram valores $>0,90$, sendo o valor teórico $(0,984)$ um pouco maior do que o unifatorial $(0,972)$.

Outro índice analisado é o RMSEA. Esse índice, segundo Hair Jr. et al. (2009), produz várias regressões, e estima-se que pode haver fatores que não são explicados por um certo número de variáveis, e, como em qualquer regressão, mostra um erro de aproximação. Valores abaixo de 0,06 indicam um bom ajuste do modelo. Isso significa que tanto o modelo teórico $(0,034)$ quanto o modelo unifatorial $(0,044)$ apresentaram um baixo erro de aproximação, sendo o valor teórico mais aceitável.

Por fim, utilizou-se o SRMR, que se refere à média padronizada dos resíduos, isto é, a discrepância entre a matriz observada e prevista (KLINE, 2005; NASCIMENTO; PIMENTEL; ADAID-CASTRO, 2016). Kline (2005) diz que valores <0,10 são considerados como bons ajustes, enquanto Nascimento et al. (2016) afirmam que valores $<0,08$ é que são considerados como indicadores de bom ajuste do modelo. Dessa forma, verificando os valores na Tabela 2, pode-se perceber também que o modelo teórico apresentou um valor de 0,049 , sendo mais baixo que o valor unifatorial. Sendo assim, é possível afirmar que ambos os modelos apresentaram coeficientes adequados, porém o modelo teórico apresenta ajustamento mais adequado do que o modelo unifatorial.

Quanto aos resultados das cargas fatoriais da AFC, todos eles estão dispostos no Diagrama de Caminhos (Figura 1), ou Path Diagram, o qual permite uma rápida visualização das relações de interdependência consideradas no modelo teórico, bem como de todos os parâmetros a serem estimados (AMORIM et al., 2012). Cabe ressaltar que foram considerados todos os itens válidos do modelo teórico para o diagrama, os quais podem ser visualizados na Figura 1. 


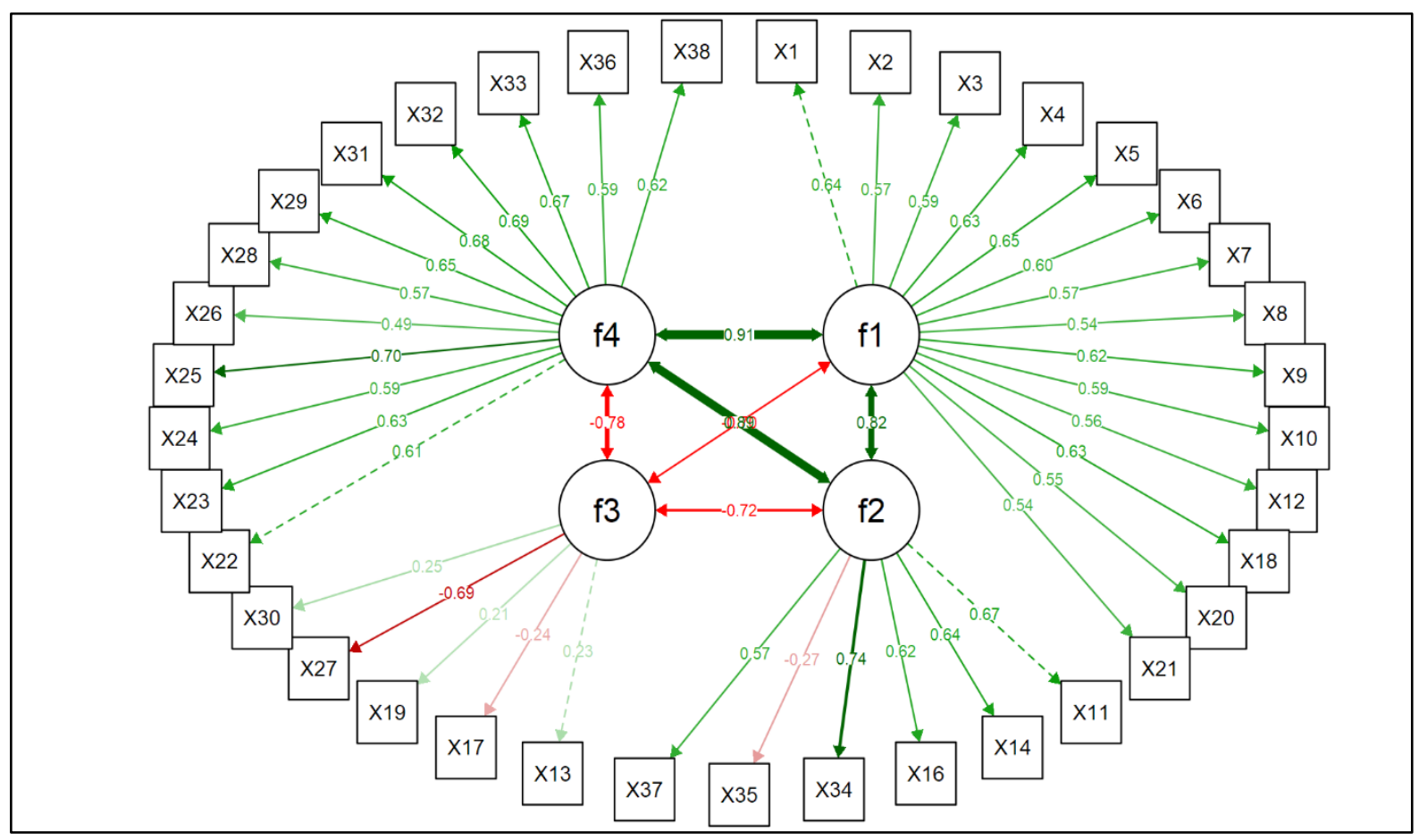

Figura 1 - Diagrama de Caminhos da Escala de Práticas Docentes para a Criatividade no Ensino Médio

Nota: $\rightarrow=$ Relação direta entre os fatores e os itens; $\leftrightarrow=$ Relação entre construtos (fatores) da mesma ordem; $\square=$ Itens da Escala; $\mathrm{O}=$ Fatores encontrados (construtos); $\mathrm{O} \rightarrow \square=$ Relação entre o Fator e o Item; $\mathrm{O} \leftrightarrow \mathrm{O}=$ Relação entre dois fatores.

Fonte: Diagrama elaborado pelas autoras, a partir dos dados da pesquisa.

Ao observar o Diagrama de Caminhos, foi possível verificar que o Fator 1, denominado "Incentivo a novas ideias", possui quatorze itens (1, 2, 3, 4, 5, 6, 7, 8, 9, 10, 12, 18, 20 e 21), assim como no modelo teórico. A carga mais baixa aparece nos itens 8 "Incentivam os estudantes a ser independentes" e 21 "Fazem perguntas relativas ao assunto que está sendo estudado", ambos com 0,54 de carga. Já no modelo teórico, a carga mais baixa, com 0,33, aparece no item 20 "Promove o debate com estímulo à participação de todos os alunos".

Ainda no Fator 1, o item que recebeu a carga fatorial mais alta no modelo hipotético $(0,65)$ foi o item 5 "Estimulam os estudantes a ampliar suas ideias a respeito dos temas estudados". Enquanto no modelo teórico, a carga mais alta $(0,78)$ esteve presente no item 10 "Leva o aluno a perceber e conhecer pontos de vistas divergentes sobre o mesmo problema ou tema de estudo".

Quanto a esse fator, Alencar e Fleith (2003), Alencar e Martínez (1998) e Ribeiro (2006) destacam que estimular, incentivar ou encorajar a independência, a iniciativa e as descobertas faz parte do desenvolvimento de habilidades criativas. Rezende (2017) também diz que a sala de aula deve estar voltada para um clima de estímulos para a criatividade. Desse modo, pode-se afirmar que o Fator 1 está bem correlacionado entre os seus itens, reforçando os resultados da Análise Fatorial Exploratória (AFE) do modelo teórico. 
Quanto ao Fator 2, denominado "Clima para expressão de ideias", ele possui seis itens $(11,14,16,34,35$ e 37), sendo que o item 35 apresenta uma correlação baixa entre o item e o fator $(-0,27)$. Na AFE do modelo teórico, esse item apresentou uma carga satisfatória, locado nesse mesmo fator, embora o fator com carga mais baixa fosse o item 11 "Valoriza as ideias originais dos alunos", com 0,39 de carga.

Ainda nesse fator, a carga mais alta no modelo hipotético aparece no item 34 "Escutam com atenção as opiniões dos alunos", com 0,74, enquanto no modelo teórico é o item 14 "Cria um ambiente de respeito e aceitação pelas ideias dos alunos" que possui maior carga, com 0,61. Isso é confirmado por Borges (2014), que afirma sobre a importância de se desenvolver um clima favorável para a expressão criativa na sala de aula.

Percebe-se que os itens desse fator, com exceção do 35, estão bem correlacionados com o fator "Clima para expressão de ideias". Hair Jr. et al. (2009) dizem que relações entre itens e fatores com valores próximos a zero indicam relações fracas, podendo tais itens serem eliminados. Desse modo, decidiu-se pela eliminação do item 35, pois, além do escore baixo, ele está estatisticamente independente dos demais itens e não contribui para a construção do fator. (HAIR JR. et al., 2009).

O Fator 3, denominado pelo modelo teórico de "Avaliação e metodologia de ensino", neste estudo, inter-relaciona-se com cinco itens (13, 17, 19, 27 e 30), sendo que aqueles com carga fatorial mais baixa são os itens 27 "Utilizam formas variadas de avaliação", com -0,69 de carga, e 17 "Utilizam formas de avaliação que exigem dos estudantes apenas a reprodução dos conteúdos mencionados nos materiais didáticos", com carga de $-0,24$.

Pode-se observar que os itens 13, 19 e 30 desse fator apresentam cargas fatoriais baixas, apesar de serem positivas. Isso significa que existe pouca correlação com o fator denominado "Avaliação e metodologia de ensino" (modelo teórico). Com exceção do item 27, os itens 13, 17, 19 e 30, na AFC do presente estudo, têm mais proximidade com o Fator "Procedimentos tradicionais de ensino". Conforme já observado anteriormente, Alencar e Fleith (2010), ao revisarem esse instrumento na percepção do professor, sugeriram a mudança do nome do fator para "Procedimentos tradicionais de ensino", o que foi feito, de modo semelhante, neste estudo.

Levando-se em consideração a nova nomenclatura do Fator 3, tanto o item 17 quanto o 27 possuem escores baixos, porém a opção foi a de deixar o item 17, pois o seu construto contribui para a construção do fator (HAIR JR. et al., 2009), e eliminar o item 27, porque, além de ter um escore baixo, o seu construto não condiz com "Procedimentos tradicionais de ensino".

É Possível verificar no Fator 4, denominado "Interesse pela aprendizagem do aluno", composto por 12 itens $(22,23,24,25,26,28,29,31,32,33,36,38)$, que, tanto no Diagrama de 
Caminhos quanto no modelo teórico, os mesmos itens se destacaram com cargas mais baixas: o 24 "Oferecem ou recomendam aos estudantes materiais adicionais referentes aos tópicos estudados" e o 26 "Têm disponibilidade para atender os estudantes em outros horários fora da sala de aula".

Porém, pode-se afirmar que a estrutura fatorial proposta oferece resultados satisfatórios, e os itens estão bem correlacionados com o fator. Wechsler (2002a) enfatiza que o grande desafio que a escola enfrenta hoje é ter professores utilizando estratégias diferenciadas. De La Torre (2012) também destaca que um professor que tem interesse pela aprendizagem do aluno possui uma atitude criativa, uma capacidade de entusiasmar, inovar, ajudar, promover a aprendizagem autônoma, variar as suas estratégias de ensino e de cultivar emocionalmente o estudante.

A realização da AFC, como vimos, permitiu-nos sustentar as dimensões fatoriais do instrumento original de Alencar e Fleith (2004) e obter dados relacionados à sua validade de construto. Analisando as relações que existem entre os construtos, pode-se perceber que, em parte, eles estão correlacionados. Isso pode ser visualizado na Figura 2.

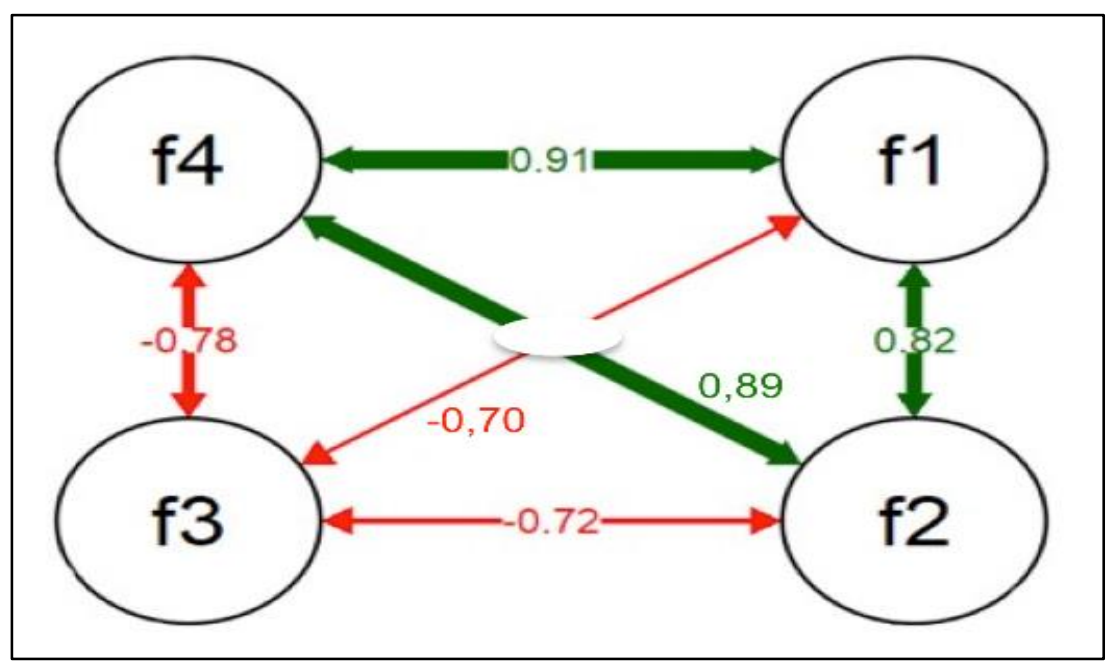

Figura 2 - Análise dos Construtos

Fonte: Diagrama elaborado pelas autoras, a partir dos dados da pesquisa.

Na Figura 2, observam-se as relações de causalidade entre os fatores, se há maior ou menor correlação de um com o outro. Laros (2012) diz que, quanto mais alto for o valor da carga fatorial, melhor o item representará o fator. Segundo Magnusson e Mourão (2005), a correlação determina se há relação entre dois fatores. Uma correlação próxima a 0 (zero) indica que duas variáveis não estão relacionadas, e, quando a correlação está mais próxima a 1 (um), isso indica uma forte relação entre os construtos, sugerindo até que possam ser condensados em um mesmo fator (HAIR JR. et al., 2009). 
Se verificarmos o Fator 1 "Incentivo a novas ideias", por exemplo, e a sua relação com os demais, podemos perceber que ele está mais relacionado com o Fator 4 "Interesse pela aprendizagem do aluno", e vice-versa. Quando há uma correlação positiva, como é o caso, as variáveis movem-se juntas (ALMEIDA; FREIRE, 2017; HAIR JR. et al. 2009), isto é, existe uma dependência dos fatores entre si, de maneira que um influencia o outro. Isso pode ser percebido, mais especificamente, nas cargas acima de 0,80 .

No entanto, também há relações negativas entre os construtos, isto é, à medida que um fator aumenta, o outro tende a diminuir. Ainda, ao analisar a Figura 2, percebe-se que o Fator 1 "Incentivo a novas ideias" tende a aumentar à medida que diminui o Fator 3 "Procedimentos tradicionais de ensino", e vice-versa. De modo semelhante, esse movimento ocorre com os Fatores 2 e 4 em relação ao Fator 3. Isso explica-se pelo fato de que os construtos com cargas fatoriais negativas ficaram todos ligados ao Fator 3 "Procedimentos tradicionais de ensino", uma vez que esse foi o único fator em que os itens indicam práticas tradicionais de ensino, e essas práticas foram entendidas como procedimentos que interferem de forma negativa no desenvolvimento da criatividade dos estudantes, em relação às práticas sugeridas nos Fatores 1, 2 e 4. Os itens que constituem esses três fatores $(1,2$ e 4 ) dizem respeito a procedimentos e características do professor em sala de aula e têm sido indicados, por diversos autores, como práticas docentes necessárias para favorecer a criatividade (ALENCAR, 2007; ALENCAR; FLEITH, 2010; AMABILE, 1999; BRAUM; CARMO; SÁ, 2016; DE LA TORRE, 2012; MARTÍNEZ, 2009; NAKANO, 2009; WECHSLER, 2017).

O Quadro 2 apresenta uma síntese dos fatores e dos seus respectivos itens extraídos do Inventário de Práticas Docentes que Favorecem a Criatividade no Ensino Superior, de Alencar e Fleith (2004), e do "Inventário de Práticas Docentes que favorecem a criatividade adaptado para o Ensino Médio", após a AFC, no presente estudo.

Quadro 2 - Fatores e seus respectivos itens extraídos do Inventário de Alencar e Fleith (2004) e do Inventário adaptado após a AFC

\begin{tabular}{|c|c|c|c|}
\hline \multicolumn{2}{|c|}{$\begin{array}{c}\text { INVENTÁRIO } \\
\text { DE ALENCAR E FLEITH (2004) }\end{array}$} & \multicolumn{2}{|c|}{$\begin{array}{l}\text { INVENTÁRIO ADAPTADO } \\
\text { APÓS A AFC }\end{array}$} \\
\hline FATORES & ITENS & FATORES & ITENS \\
\hline Incentivo a novas ideias & $\begin{array}{l}1,2,3,4,5,6,7,8,9,10 \\
12,18,20,21\end{array}$ & Incentivo a novas ideias & $\begin{array}{l}1,2,3,4,5,6,7,8,9,10, \\
12,18,20,21\end{array}$ \\
\hline $\begin{array}{l}\text { Clima para expressão de } \\
\text { ideias }\end{array}$ & $11,14,16,34,35,37$ & $\begin{array}{l}\text { Clima para expressão de } \\
\text { ideias }\end{array}$ & $11,14,16,34,37$ \\
\hline $\begin{array}{l}\text { Avaliação e metodologias } \\
\text { de ensino }\end{array}$ & $13,17,19,27,30$ & $\begin{array}{l}\text { Procedimentos } \\
\text { tradicionais de ensino }\end{array}$ & $13,17,19,30$ \\
\hline
\end{tabular}




\begin{tabular}{|c|c|c|c|}
\hline $\begin{array}{l}\text { Interesse pela } \\
\text { aprendizagem do aluno }\end{array}$ & $\begin{array}{l}22,23,24,25,26,28,29 \\
31,32,33,36,38\end{array}$ & $\begin{array}{l}\text { Interesse pela } \\
\text { aprendizagem do aluno }\end{array}$ & $\begin{array}{l}22,23,24,25,26,28,29, \\
31,32,33,36,38\end{array}$ \\
\hline \multicolumn{4}{|c|}{ ITENS ELIMINADOS } \\
\hline \multicolumn{2}{|c|}{15} & \multicolumn{2}{|c|}{27,35} \\
\hline \multicolumn{4}{|c|}{ TOTAL DE ITENS DA ESCALA } \\
\hline \multicolumn{2}{|c|}{37} & \multicolumn{2}{|c|}{35} \\
\hline
\end{tabular}

Fonte: Quadro elaborado pelas autoras, a partir dos dados da pesquisa.

Ante a versão do Inventário de Práticas Docentes que Favorecem a Criatividade no Ensino Superior, desenvolvido por Alencar e Fleith (2004), no presente estudo, para a versão final do instrumento denominado "Inventário de Práticas Docentes que favorecem a criatividade no Ensino Médio”, foram mantidos os 4 fatores com um total de 35 itens, sendo eliminados os itens 15, 27 e 35. Isso é relativamente frequente na solução encontrada na AFE, pelo motivo de os itens apresentarem ajustes diferentes testados pela AFC, independentemente da matriz ou da amostra utilizada (LORENZO-SEVA; VAN GINKEL, 2016).

Com esses resultados encontrados, o "Inventário de Práticas Docentes que favorecem a criatividade no Ensino Médio" atendeu aos objetivos deste estudo. Assim, a adaptação e a conferição das evidências de validade desse instrumento reforçam as suas qualidades psicométricas, indicando, de modo confiável, sua aplicabilidade em futuros estudos sobre o que pensam os estudantes do Ensino Médio em relação às práticas docentes criativas no cotidiano da sala de aula. Os dados desta interpretação são relevantes para a criatividade no contexto educacional sob um olhar duplo: em relação ao estudante, eles podem consistir em um recurso que exercita a sua sensibilidade aos processos de criação; já para o professor, podem viabilizar a compreensão acerca do modo como as suas práticas são interpretadas por seus alunos, além de oferecerem subsídios para ele encontrar alternativas de ensino criativo. Esses olhares são considerados necessários para que haja criatividade na escola (OLIVEIRA; ALENCAR, 2008).

A participação do estudante do Ensino Médio em processos criativos é um dos eixos estruturantes dos itinerários formativos prescritos pelos Referenciais Curriculares para o Ensino Médio, os quais exigem, como fogo pedagógico, o trabalho com projetos criativos, com o objetivo de ampliar as capacidades relacionadas ao pensar e de construir soluções inovadoras para os problemas identificados (MINISTÉRIO DA EDUCAÇÃO, 2018). Esse tipo de iniciativa reforça, em termos práticos, a contribuição da aplicabilidade do "Inventário de Práticas Docentes que favorecem a criatividade no Ensino Médio" por parte dos profissionais da educação, de modo que a compreensão e interpretação das práticas docentes que interferem na criatividade ampliem o conhecimento relacionado ao fazer criativo no contexto educacional. 


\section{CONSIDERAÇÕES FINAIS}

Dada a relevância da criatividade no contexto do ensino e da aprendizagem, considerada competência do século XXI e confirmada por Porto e Wechsler (2020), os dados obtidos neste estudo de adaptação do Inventário de Práticas Docentes que Favorecem a Criatividade no Ensino Superior para o contexto do Ensino Médio e de suas evidências de validade estendem-se além dos aspectos que devem ser contemplados nos procedimentos de evidências de validade de um construto ou de um teste. A partir de um olhar mais amplo, vale ressaltar que é importante tanto as análises quantitativas, com auxílio da estatística, quanto os passos de operacionalização de âmbito qualitativo para a adequação da semântica, com o público-alvo, e da percepção demonstrada, por esse público, na identificação das práticas criativas de seus professores. Haja vista que essas práticas criativas dos docentes, no cotidiano da sala de aula, são relevantes para o desempenho dos estudantes, independentemente do seu nível de escolaridade, além de contribuírem com a reflexão do professor, a partir da escuta sobre o que pensam, com relação às suas práticas, seus alunos, e, até mesmo, elas podem estimular a introdução de novas práticas que favoreçam o desenvolvimento do potencial criativo do professor e do estudante.

Apesar das contribuições do presente estudo, há limitações a serem apontadas. Cabe mencionar, a respeito da amostra utilizada, que esta foi constituída por estudantes de várias unidades escolares, em diversas regiões do Brasil, de uma única rede de ensino particular. Portanto, sugere-se a ampliação da amostra a fim de incluir estudantes de outras redes de ensino particulares e públicas no Brasil, bem como expandir para outros países, além disso há a possibilidade da inclusão de outras variáveis nos futuros estudos. Tais fatores ampliariam a compreensão de um fenômeno tão complexo como a criatividade no contexto das práticas docentes, além de possibilitarem a obtenção de parâmetros comparativos dos resultados.

Em relação aos resultados, as diferenças entre as instituições públicas e particulares podem ser entendidas por vários fatores que influenciam a existência e o desenvolvimento dos fenômenos a serem observados em relação à produção criativa em sala de aula. Sobre isso, Alencar, Fleith, Boruchovitch e Borges (2015) ressaltam que as diferenças entre esses contextos podem ser entendidas sob vários pontos de vista, tais como: da clientela e da formação dos professores de cada tipo de escola, dos estereótipos e dos preconceitos a respeito da rede pública de ensino em relação à rede particular, dentre outros. Inclusive, outros fatores, tais como: a estrutura curricular, as condições de trabalho, o conhecimento dos professores acerca de práticas estimuladoras do potencial criativo em sala de aula, os princípios filosóficos e metodológicos que norteiam a 
proposta pedagógica, podem influenciar as práticas docentes, independentemente da diversidade social e cultural provenientes do contexto regional de cada escola, seja no âmbito público ou privado.

Outra limitação refere-se à percepção dos estudantes sobre as práticas criativas dos seus professores de modo individual e não coletivo, além das dificuldades na coleta de dados que podem se manifestar, devido ao tempo necessário para se preencher o inventário, uma vez que o currículo do Ensino Médio contempla diversas áreas do conhecimento, haja vista a diversidade de professores. Nessa direção, os dados tornam-se mais relevantes para a reflexão de cada professor, bem como permitem a verificação de possíveis aproximações e diferenças entre as áreas, em relação às práticas docentes criativas na percepção dos estudantes.

Por essas razões, destaca-se a relevância do uso desse instrumento com amostras mais amplas, especialmente para levar em consideração a grande diversidade do sistema educacional brasileiro (privado e público), os diferentes níveis de escolarização, as diferentes áreas do conhecimento, as diversidades culturais, sociais e econômicas e as análises comparativas com estudos transculturais. Isso ampliaria as possibilidades de se avançar no aperfeiçoamento ou na inclusão de novas práticas que estimulem a criatividade no cotidiano da sala de aula.

Posto isso, a versão final do instrumento denominado "Inventário de práticas docentes que favorecem a criatividade no Ensino Médio", com características psicométricas adequadas, constitui-se em uma ferramenta que abre novas perspectivas nesse contexto, para fins de futuras pesquisas, e auxilia nas atitudes, no âmbito educacional, quanto ao estímulo à criatividade. No que diz respeito às implicações práticas, recomenda-se que esse inventário seja aplicado em diferentes instituições do Ensino Médio, no intuito de contribuir para a reflexão do professor quanto à sua atuação em sala de aula, em relação às suas estratégias de ensino, aos recursos e aos tipos de atividades que desenvolve no seu cotidiano escolar. Cabe ressaltar a pertinência dessas reflexões para a construção da identidade do docente, com vistas à sua formação continuada, de modo que o repensar sobre as práticas docentes estimule a criatividade em sala de aula, beneficiando o ensino e a aprendizagem ao desenvolver a criatividade na docência e favorecendo a expressão criativa dos estudantes. Sendo o fim último o que requer a contemporaneidade: professores criativos e aptos para formarem alunos criativos (OLIVEIRA; ALENCAR, 2008).

\section{REFERÊNCIAS}

ALENCAR, E. M. L. S. O contexto educacional e sua influência na criatividade. Linhas Críticas, v. 8, n. 15, p. 165-178, 2002. Disponível em: https://periodicos.unb.br/index.php/linhascriticas/article/view/3055. Acesso em: 12 maio 
2018.

ALENCAR, E. M. L. S. Criatividade no contexto educacional: três décadas de pesquisa. Psicologia: Teoria e Pesquisa, São Paulo, v. 23, n. 5, p. 45-49, 2007. Disponível em: https://www.scielo.br/pdf/ptp/v23nspe/07.pdf. Acesso em: 12 maio 2018.

ALENCAR, E. M. L. S.; FLEITH, D. S. Criatividade: Múltiplas Perspectivas. 3. ed. Brasília: Editora UNB, 2003.

ALENCAR, E. M. L. S.; FLEITH, D. S. Inventário de práticas docentes que favorecem a criatividade no Ensino Superior. Psicologia: reflexão e crítica, Rio Grande do Sul, v. 17, n. 1, p. 105110, 2004. Disponível em: https://www.scielo.br/pdf/prc/v17n1/22310.pdf. Acesso em: 12 maio 2018.

ALENCAR, E. M. L. S.; FLEITH, D. S. Escala de Práticas Docentes para a Criatividade na Educação Superior. Avaliação Psicológica, Brasília, v. 9, n. 1, p. 13-24, 2010. Disponível: em maio 12, 2018, de http://pepsic.bvsalud.org/pdf/avp/v9n1/v9n1a03.pdf. Acesso em: 12 maio 2018.

ALENCAR, E. M. L. S.; MARTÍNEZ, A. M. Barreiras à expressão da criatividade entre profissionais brasileiros, cubanos e portugueses. Psicologia Escolar e Educacional, Uberlândia, MG, v. 2, n. 1, p. 23-32, 1998. Disponível em: https://www.scielo.br/pdf/pee/v2n1/v2n1a03.pdf. Acesso em: 12 maio 2018.

ALENCAR, E. M. L. S.; BRUNO-FARIA, M. F.; FLEITH, D. S. Medidas de criatividade: teoria e prática. Porto Alegre: Artmed Editora, 2010.

ALENCAR, E. M. L. S.; FLEITH, D. S.; BORUCHOVITCH, E.; BORGES, C. N. Criatividade no Ensino Fundamental: Fatores Inibidores e Facilitadores segundo Gestores Educacionais. Psicologia: Teoria e Pesquisa, v. 31, n. 1, p. 105-114, 2015. Disponível em: https://www.scielo.br/pdf/ptp/v31n1/0102-3772-ptp-31-01-0105.pdf. Acesso em: 10 maio 2019.

ALMEIDA, J. M. O. O Ensino Médio e as Práticas Docentes adotadas para expressão e desenvolvimento da Criatividade. 2010. Dissertação (Mestrado) - Universidade Católica de Brasília, Brasília, DF, 2010. Disponível em: https://bdtd.ucb.br:8443/jspui/bitstream/123456789/865/1/Texto\%20Completo.pdf. Acesso em: 10 maio 2019.

ALMEIDA, L. S.; FREIRE, T. Metodologia da investigação em psicologia e educação. 5. ed. Braga: Psiquilíbrios, 2017.

AMABILE, T. M. Como não matar a criatividade. HSM Management, São Paulo, v. 12, n. 12, p. 110-115, 1999.

AMORIM, L.; FIACCONE, D. A. F.; SANTOS, R.; MORAES, C.; OLIVEIRA, L.; OLIVEIRA, N.; SANTOS, T. N. L. Modelos de equações estruturais: princípios básicos e aplicações. Relatório Técnico do Instituto de Matemática da UFBA, Salvador, BA, Brasil, 2012. Disponível em: https://repositorio.ufba.br/ri/bitstream/ri/17684/1/ebook_SEM_2012.pdf. Acesso em: 10 maio 2019.

BATISTA, E. C.; LUZ, E. N.; BRUM, A. L. O. Autopercepção sobre as práticas docentes para o desenvolvimento da criatividade em uma instituição de Ensino Superior da Amazônia. Revista Intersaberes, Paraná, v. 10, n. 21, p. 595-699, 2015. Disponível em: 
https://www.uninter.com/intersaberes/index.php/revista/article/view/769/505. Acesso em: 10 maio 2019.

BENTLER, P. M.; BONETT, D. G. Significance tests and goodness of fit in the analysis of covariance structures. Psychological Bulletin, v. 88, n. 3, p. 588-606, 1980. DOI: 10.1037/00332909.88.3.588.

BORGES, C. N. Uso de tecnologias na prática pedagógica e sua influência na criatividade, clima de sala de aula e motivação para aprender. 2014. Dissertação (Mestrado) - Universidade Católica de Brasília, Brasília, DF, 2014. Disponível em: http://repositorio.unb.br/handle/10482/15767. Acesso em: 10 abr. 2019.

BRAUM, L. M. S.; CARMO, H. M. O.; SÁ, E. V. Criatividade no Ensino Superior: uma análise da percepção dos discentes sobre as práticas dos docentes. Revista Capital Científico, Paraná, v. 14, n. 4, out./dez. 2016. Disponível em:

https://revistas.unicentro.br/index.php/capitalcientifico/article/view/4159/3155. Acesso em: 10 abr. 2019.

BRICEÑO, E. D. Desarrollo de competências docentes em el profesorado universitário: la solución creativa de problemas. 2014. Tese (Doutorado) - Universidade de Granada, Espanha, 2014. Disponível em: https://hera.ugr.es/tesisugr/2418052x.pdf. Acesso em: 10 abr. 2019.

BROWN, T. A. Confirmatory factor analysis for applied research. New York: Guilford Publications, 2015.

CASSEP-BORGES, V.; BALBINOTTT, M. A. A.; TEODORO, M. L. M. Tradução e validação de conteúdo: uma proposta para a adaptação de instrumentos. In: PASQUALI, L. (org.).

Instrumentação Psicologica: fundamentos e práticas. Porto Alegre: ArtMed, 2010. p. 506-520.

CASSOL, A.; CANELA, R.; RUAS, J. L. Análise da perspectiva da criatividade implícita em práticas docentes no Ensino em Administração: o caso de instituições de Ensino Superior de Santa Catarina. III SIMPÓSIO INTERNACIONAL DE GESTÃO DE PROJETO (III SINGEP) e II SIMPÓSIO INTERNACIONAL DE INOVAÇÃO E SUSTENTABILIDADE (II S2IS). Anais [...]. São Paulo, 2014. Disponível em:

http://repositorio.uninove.br/xmlui/bitstream/handle/123456789/1071/430.pdf?sequence=1. Acesso em: 10 abr. 2019.

CSIKSZENTMIHALYI, M. Creativity: Flow and the psychology of discovery and invention. New York: Harper Perennial, 2007. chap. 5, p. 107-127.

DAMÁSIO, B. F. Uso da análise fatorial exploratória em psicologia. Avaliaşão Psicológica, Itatiba, v. 11, n. 2, p. 213-228, 2012. Disponível em:

http://pepsic.bvsalud.org/scielo.php?script=sci_arttext\&pid=S1677-04712012000200007.

Acesso em: 10 abr. 2019.

DE LA TORRE, S.; VIOLANT, V. Comprender y evaluar la creatividad. Espanha: Ediciones Aljibe, 2006, v. 1.

DE LA TORRE, S. Criatividade Aplicada: recursos para uma formação criativa. São Paulo: Madras, 2008.

DE LA TORRE, S. Instituciones educativas creativas: Instrumento para valorar el desarrollo de instituciones creativas - VADECRIE. Barcelona: Circulo Rojo, 2012. 
FADEL, S. J. Avaliação de um programa de criatividade para professores do Ensino Superior. 2010. Tese (Doutorado) - Pontifícia Universidade Católica de Campinas, Campinas, SP, 2010. Disponível em: http://tede.bibliotecadigital.puc-campinas.edu.br:8080/jspui/handle/tede/419. Acesso em: 10 abr. 2019.

FLEITH, D. S.; ALENCAR, E. M. L. S. Escala sobre o clima para criatividade em sala de aula. Psicologia: Teoria e Pesquisa, Brasília, v. 21, n. 1, p. 85-91, 2005. Disponível em: https://www.scielo.br/scielo.php?script=sci_arttext\&pid=S0102-37722005000100012. Acesso em: 20 jan. 2019.

FLEITH, D. S.; ALENCAR, E. M. L. S. Percepção de estudantes do ensino fundamental quanto ao clima de sala de aula para criatividade. Psicologia em Estudo, Paraná, v. 11, n. 3, p. 513-521, 2006. Disponível em: https://www.scielo.br/pdf/pe/v11n3/v11n3a06.pdf. Acesso em: 20 jan. 2019.

FLEITH, D. S.; ALENCAR, E. M. L. S. Características personológicas e fatores ambientais relacionados à criatividade do estudante do Ensino Fundamental. RS: Avaliação psicológica, Porto Alegre, v. 7, n. 1, p. 35-44, 2008. Disponível em: http://pepsic.bvsalud.org/pdf/avp/v7n1/v7n1a06.pdf. Acesso em: 20 jan. 2019.

FLEITH, D. S.; ALMEIDA, L. S.; PEIXOTO, F. J. B. Validação da escala clima para criatividade em sala de aula. Estudos de psicologia, Campinas, v. 28, n. 3, p. 307-314, set. 2011. Disponível em: https://www.scielo.br/pdf/estpsi/v28n3/a02v28n3.pdf. Acesso em: 20 jan. 2019.

FROSSARD, F. Fostering teacher's creativity through the creation of GBL scenarios. Barcelona, Espanha: Universitad de Barcelona, 2013.

GONTIJO, C. H. Relações entre criatividade, criatividade em Matemática e motivação em Matemática de estudantes do Ensino Médio. 2007. Tese (Doutorado) - Universidade Católica de Brasília, Brasília, DF, 2007. Disponível em: http://repositorio.unb.br/handle/10482/2528. Acesso em: 20 jan. 2019.

GÜNTHER, H. Como elaborar um questionário. Brasília, DF: UnB, Laboratório de Psicologia Ambiental, 2003. (Série Planejamento de Pesquisa nas Ciências Sociais, n. 1).

HAETINGER, M. G. Aprendizagem Criativa - Educadores Motivados para enfrentar os desafios do novo século: educação a distância, redes de aprendizagem, criatividade e motivação. Rio de Janeiro: Wak Editora, 2012.

HEIDEMANN, L. A.; OLIVEIRA, A. M. M.; VEIT, E. A. Ferramentas on-line no ensino de ciências: uma proposta com o Google Docs. Física na Escola, v. 11, n. 2, p. 30-33, 2010.

Disponível em:

https://www.lume.ufrgs.br/bitstream/handle/10183/116446/000792476.pdf?sequence=1\&isAll owed $=$ y. Acesso em: 20 jan. 2019.

HAIR, J. F. Jr.; ANDERSON, R. E.; TATHAM, R. L.; BLACK, W. C. Análise multivariada de dados. Tradução Adonai Schlup Sant'Anna. 6. ed. Porto Alegre: Bookman, 2009.

JAUK, E.; EBERHARDT, L.; KOSCHMIEDER, C.; DIEDRICH, J.; PRETSCH, J.; BENEDEK, M.; NEUBAUER, A. C. A New Measure for the Assessment of Appreciation for Creative Personality. Creativity Research Journal, v. 31, n. 2, p. 149-163, 2019. DOI: https://doi.org/10.1080/10400419.2019.1606622.

JÖRSKOG, K. G.; SÖRBOM, D. Advances in factor analysis and structural equation models. 
Cambridge, MA: Abt Books, 2012.

KAUFMAN, J. C. Creativity as a stepping stone toward a brighter future. Journal of Intelligence, v. 6, n. 2, 2018. DOI: https://doi.org/10.3390/jintelligence6020021.

KLINE, R. B. Principles and practice of structural equation modeling. 2th ed. New York: The Guilford Press, 2005.

LAROS, J. A. O uso da Análise Fatorial: Algumas diretrizes para pesquisadores. In: PASQUALI, L. (ed.). Análise Fatorial para Pesquisadores. Brasília: LabPAM Saber e Tecnologia, 2012. p. 141-160.

LIBÓRIO, A. C. O. As interações professor-estudante e o clima para a criatividade em sala de aula: Possivieis relações. Dissertação (Mestrado) - Universidade Católica de Brasília, Brasília, 2009. Disponível em: http://bdtd.ibict.br/vufind/Record/UNB_f67017aeb6448cb3bdaecc1506c47685. Acesso em: 20 jan. 2019.

LOPES, J. A comunicaşão verbal e não-verbal de docentes do ensino médio e o processo de ensino-aprendizagem: um estudo de caso. Dissertação (Mestrado) - Universidade Fernando Pessoa, Porto, Lisboa, 2018. Disponível em:

https://bdigital.ufp.pt/bitstream/10284/6762/1/DM_J\%C3\%B3dna\%20Lopes.pdf. Acesso em: 20 jan. 2019.

LORENZO-SEVA, U.; VAN GINKEL, J. R. Multiple Imputation of missing values in exploratory factor analysis of multidimensional scales: Estimating latent trait scores. Anales de Psicología, Universidad de Murcia, Espanha, v. 32, n. 2, p. 596-608, 2016. DOI: https://doi.org/ 10.6018/analesps.32.2.215161.

LUBART, T. Psicologia da criatividade. Porto Alegre: Artmed Editora, 2009.

MACCALUM, R. C.; WIDAMAN, K. F.; ZHANG, S.; HONG, S. Shang Sample size in factor analysis. Psychological Methods, v. 4, n. 1, p. 84-99, 1999. DOI: https://doi.org/10.1037/1082989X.4.1.84.

MAGNUSSON, W. E.; MOURAO, G. Estatística sem matemática. Londrina: Ed. Planta, 2005.

MARÔCO, J. Análise de equacõoes estruturais. Lisboa, Portugal: ReportNumber, 2010.

MARTÍNEZ, A. M. Criatividade, Personalidade e Educaşão. Campinas: Papirus, 1997.

MARTÍNEZ, A. M. A criatividade na escola: três direções de trabalho. Linhas Críticas, Brasília, v. 8, n. 15, p. 189-206, 2002. Disponível em:

https://periodicos.unb.br/index.php/linhascriticas/issue/view/254. Acesso em: 20 jan. 2019.

MARTÍNEZ, A. M. Criatividade no trabalho pedagógico e criatividade na aprendizagem: uma relação necessária? In: TACCA, M. C. V. R. (ed.). Aprendizagem e trabalho pedagógico. Campinas: Alínea, 2008.

MARTÍNEZ, A. M. Processos de aprendizagem na pós-graduação: um estudo exploratório. In: MARTÍNEZ, A. M. M.; TACCA, C. V. R. (ed.). A complexidade da aprendizagem: destaque ao Ensino Superior. Campinas: Alínea, 2009. p. 213-262.

MATHIAS, S.; SAKAI, C. Utilização da Ferramenta Google Forms no Processo de Avaliação Institucional: Estudo de Caso nas Faculdades Magsul. 2012. Disponível em: 
http://download.inep.gov.br/educacao_superior/avaliacao_institucional/seminarios_regionais/t rabalhos_regiao/2013/centro_oeste/eixo_1/google_forms_processo_avaliacao_instit_estudo_ca so_faculdades_mag.pdf. Acesso em: 20 jan. 2019.

MILIAN, Q. G. Evidências de validade da bateria de avaliação intelectual e criativa - BAICA. Dissertação (Mestrado) - Pontifícia Universidade Católica de Campinas, Campinas, SP, 2014. Disponível em: http://tede.bibliotecadigital.puc-campinas.edu.br:8080/jspui/handle/tede/330. Acesso em: 20 jan. 2019.

MINISTÉRIO DA EDUCAÇÃO. Referenciais Curriculares para a elaboração de Itinerários Formativos. 2018. Disponível em: https://pt.scribd.com/document/404957441/Referenciais-Curricularespara-Elaboracao-de-Itinerarios-Formativos-pdf. Acesso em: 20 jan. 2019.

MORAIS, M. F.; ALMEIDA, L. S.; AZEVEDO, I.; ALENCAR, E. M. L. S.; FLEITH, D. S. Validação portuguesa do Inventário de Práticas Docentes para a Criatividade na Educação Superior. Avaliação Psicológica, Porto Alegre, RS, v. 13, n. 2, p. 167-175, 2014. Disponível em: http://pepsic.bvsalud.org/pdf/avp/v13n2/v13n2a04.pdf. Acesso em: 20 jan. 2019.

NAKANO, T. C. Teste brasileiro de criatividade infantil: normatização de instrumento no ensino fundamental. Tese (Doutorado) - Pontifícia Universidade Católica de Campinas, Campinas, São Paulo, 2006. Disponível em: http://tede.bibliotecadigital.puccampinas.edu.br:8080/jspui/handle/tede/371. Acesso em: 20 jan. 2019.

NAKANO, T. C. Investigando a criatividade junto a professores: pesquisas brasileiras. Psicologia Escolar e Educacional, Campinas, v. 13. n. 1, p. 45-53, jun. 2009. Disponível em: https://www.scielo.br/pdf/pee/v13n1/v13n1a06.pdf. Acesso em: 20 jan. 2019.

NAKANO, T. C. Programas de treinamento em criatividade: conhecendo as práticas e resultados. Psicologia Escolar e Educacional, Campinas, v. 15, n. 2, p. 311-322, 2011. Disponível em: https://www.scielo.br/pdf/pee/v15n2/v15n2a13.pdf. Acesso em: 20 jan. 2019.

NASCIMENTO, T. G.; PIMENTEL, C. E.; ADIAD-CASTRO, B. G. Escala de Atitudes frente à Arma de Fogo (EAFAF): Evidências de Sua Adequação Psicométrica. Psicologia: Teoria e Pesquisa, Brasília, v. 32, n. 1, p. 239-248, 2016. Disponível em: https://www.scielo.br/pdf/ptp/v32n1/1806-3446-ptp-32-01-00239.pdf. Acesso em: 20 jan. 2019.

NORONHA, A. P. P.; PINTO, L. P.; OTTATI, F. Análise fatorial confirmatória da Escala de Aconselhamento Profissional. Arq. Bras. Psicol., Rio de Janeiro, v. 68, n. 1, p. 62-71, abr. 2016. Disponível em: http://pepsic.bvsalud.org/scielo.php?script=sci_arttext\&pid=S180952672016000100006\&lng=p t\&nrm=iso. Acesso em: 20 jan. 2019.

NUÑEZ, I. B.; SANTOS, F. A. A. O professor e a formação docente: a criatividade e as crenças educativas onde estão? Holos, Rio Grande do Norte, v. 2, n. 28, p. 148-165, 2012. Disponível em: https://www.researchgate.net/publication/274120883_O_PROFESSOR_E_A_FORMACAO_ DOCENTE_A_CRIATIVIDADE_E_AS_CRENÇAS_EDUCATIVAS_ONDE_ESTAO. Acesso em: 20 jan. 2019.

OLIVEIRA, Z. M. F.; ALENCAR, E. M. L. S. A criatividade faz a diferença na escola: o professor e o ambiente criativos. Contrapontos, v. 8, n. 2, p. 295-306, 2008. Disponível em: www6.univali.br/seer/index.php/rc/article/download/954/810. Acesso em: 20 jan. 2019. 
OLIVEIRA, E. B. P.; ALENCAR, E. M. L. S. Características de professores criativos e de coordenadores que estimulam a criatividade docente. Boletim Academia Paulista de Psicologia, São Paulo: v. 30, n. 79, p. 379-393, 2010.

PORTO, L. A. A. A.; WECHSLER, S. M. Panorama do Ensino de Criatividade e Inovação no Brasil. Revista Ibero-Americana de Criatividade e Inovação, v. 1, n. 1, p. 27-40, 2020. Disponível em: https://recriai.emnuvens.com.br/revista/article/view/22. Acesso em: 15 ago. 2020.

PRIMI, R.; MUNIZ, M.; NUNES, C. H. S. S. Definições contemporâneas de validade de testes psicológicos. In: HUTZ, C. S. (org.). Avanços e polêmicas em avaliação psicológica. São Paulo: Casa do Psicólogo, 2009, p. 243-266.

REZENDE, D. V. Uso criativo das tecnologias da informação e comunicação na educação superior: atuação de professores e percepção de estudantes. 2017. Tese (Doutorado) - Universidade Católica de Brasília, Brasília, DF, 2017. Disponível em: http:// repositorio.unb.br/handle/10482/23479. Acesso em: 12 maio 2018.

RIBEIRO, R. A. Percepção de professores e estudantes de cursos de licenciatura quanto ao estímulo à criatividade. Dissertação (Mestrado) - Universidade Católica de Brasília, Brasília, DF, 2006. Disponível em: https://repositorio.unb.br/handle/10482/9222. Acesso em: 12 maio 2018.

RIBEIRO, R. A.; FLEITH, D. S. O estímulo à criatividade em curso de licenciatura. Paideia, São Paulo, v. 17, n. 38, p. 403-416, 2007. Disponível em:

https://www.scielo.br/pdf/paideia/v17n38/v17n38a10.pdf. Acesso em: 12 maio 2018.

SATHLER, T. C. Desenvolvimento da criatividade na Educação à Distância segundo a percep̧̧ão de Universitários. Dissertação (Mestrado) - Universidade de Brasília, Brasília, 2007. Disponível em: https://repositorio.unb.br/handle/10482/3238. Acesso em: 12 maio 2018.

SCRABIS-FLETCHER, K.; SILVERMAN, S. Perception of Competence in Middle School Physical Education: Instrument Development and Validation. Research Quarterly for Exercise and Sport, Australia, v. 81, n. 1, p. 53-61, 2010. DOI:

https://doi.org/10.1080/02701367.2010.10599627.

SILVA, G. O. L.; FADEL, S. J.; WECHSLER, S. M. Criatividade e educação: análise da produção científica brasileira. EccoS - Revista Científica, São Paulo, n. 30, p. 165-181, jan./abr. 2013. Disponível em:

https: / periodicos.uninove.br/index.php?journal $=$ eccos\&page $=$ article\&op $=$ view\&path $\% 5 \mathrm{~B} \% 5$ $\mathrm{D}=2183 \&$ path $\% 5 \mathrm{~B} \% 5 \mathrm{D}=2239$. Acesso em: 12 maio 2018 .

SUÁREZ, J. T. Identificação de talentos criativos e intelectuais por testes psicológicos e percepção dos professores. 2014. Dissertação (Mestrado) - Pontifícia Universidade Católica de Campinas, Campinas, São Paulo, 2014. Disponível em: http://tede.bibliotecadigital.puccampinas.edu.br:8080/jspui/handle/tede/332. Acesso em: 12 maio 2018.

TORRANCE, E. P. Why Fly? A philosophy of creativity. Norwood, NJ: Ablex, 1995.

VINCENT-LANCRIN, S.; GONZÁLEZ-SANCHO, C.; BOUCKAERT, M.; LUCA, F.; FERNÁNDEZ-BARRERA, M.; JACOTIN, G.; URGEL, J.; VIDAL, Q. Desenvolvimento da criatividade e do pensamento crítico dos estudantes: o que significa na escola. São Paulo: Fundação Santillana, 2020. 
WECHSLER, S. M. Avaliação da criatividade por figuras e palavras -Testes de Torrance, versão brasileira. Campinas: LAMP/PUC-Campinas, 2002a.

WECHSLER, S. M. Criatividade e desempenho escolar: uma síntese necessária. Linhas Críticas. Brasília, v. 8, n. 15, p. 179-188, 2002b. Disponível em:

https://periodicos.unb.br/index.php/linhascriticas/article/view/3056. Acesso em: 12 maio 2018.

WECHSLER, S. M. Avaliação da criatividade verbal no contexto brasileiro. Avaliação Psicológica, Porto Alegre, v. 3, n. 1, p. 21-31, 2004. Disponível em:

http://pepsic.bvsalud.org/pdf/avp/v3n1/v3n1a03.pdf. Acesso em: 12 maio 2018.

WECHSLER, S. M. Criatividade e Inovação: O impacto de uma educação estimuladora. II Congresso Internacional de Criatividade e Inovação, Pontifícia Universidade Católica de Campinas, Campinas, SP, Brasil, 2017. Disponível em: http://www.criabrasilis.org.br/ arquivos/pdfs/100_criatividade.pdf. Acesso em: 12 maio 2018.

WECHSLER, S. M.; NAKANO, T. C. Criatividade no ensino superior: uma perspectiva internacional. São Paulo: Editora Vetor, 2011.

Submetido: $19 / 11 / 2019$

Aprovado: $15 / 09 / 2020$ 